\title{
THE RELATIONSHIP BETWEEN EDUCATIONAL LEVEL AND CHOICE SEFL-MEDICATION OR PROFESSIONAL HEALTH CARE PROVIDERS OF PATIENTS IN HOCHIMINH CITY
}

\author{
Pham Quang Anh Thu
}

\begin{abstract}
Self-medication is a common practice in many developing countries. In Vietnam, self-medication has grown in recent years due to the increasing availability of drug vendors and pharmacy shops throughout the country. Beside the convenience, time and cost saving, self-medication is associated with risks such as misdiagnosis, use of irrational drug dosage that lead to the harmful consequences not only for patient himself but also for community as a whole.

This study focuses on examining the impact of educational level on self-medication practice in Ho Chi Minh city, the national center of educational and health care of the country. The descriptive statistics and econometric analyzes have been applied to answer the question whether the adult individuals with a higher education are more likely to be self-medicated. The study had been employed the theory of consumer choice as the foundation theory, the Andersen's behaviour model, and two empirical studies to construct a health-seeking model which describes the way individuals make choices regarding health care utilization to get the highest level of utility.

The findings based on the survey conducted by the author in Ho Chi Minh city show that the more educated individual is, the more self-medication they have in treating minor illness. However, the level knowledge of safe medicine use is relatively low among patients.
\end{abstract}

Keywords: Self-medication, professional health care provider, types of illnesses.

\section{INTRODUCTION}

After the economics reform initiated in 1986 in Vietnam, the role of public health sector began to deteriorate which accompanied the emergence of private sector and the expanding of pharmaceutical industry. The rapidly expanding drug vendors and pharmacy shops throughout the country has emerged now acting as an important healthcare provider. According to the Vietnam National Health Survey 2001-2002, self-medication is very common practice to deal with illness among Vietnamese households -
73 percent of patients reporting use of self-medication to deal with illness and most people procure medication for selfmedication at pharmacists.

The common practice of selfmedication has both positive and negative aspects. In cases of common illness selfmedication may be rational behaviour in terms of convenient, time saving and cheap if patients have sufficient knowledge about common non-prescription drugs. But in cases of more serious disease, requiring the use of antibiotics or steroids, or in cases of special status such as pregnancy, 
babies, people with drug allergies, the treatment without consultation of medical professionals can lead to harmful consequences. In the latter cases, selfmedication accompanied the lack of ability or awareness of the need to read the drug information lead to a risky of wasting money, status of sickness may be more serious. The negative sides of selfmedication are not only affecting on the patient chose it but also on the community (VNHS, 2002).

The promotion of the rational drugs use to minimize the negatives effects on the public health when the self-medication practice is prevalence in Vietnam is the emerging concern of health policy makers. On the demand side, the knowledge, attitudes, and education of an individual are important determinants in the decision to seeking health care. Examining the impact of education on attitude toward self-medication of individuals when they being illness is helpful for the health policy maker who interested in improving the appropriate access of self-medication in public. This also is the main purpose of this study.

\section{LITERATURE REVIEW}

\section{SOME DEFINITIONS}

Self-medication: Self-medication is the use of drugs or having any pharmacy visits/consultations to treat self-diagnosed, or the interruptedness or continued use of a prescribed drug for chronic or recurrent disease or symptoms without any previous contact with other health care professional providers (WHO, 2001).

Professional health care provider: In the framework of this study, professional health care provider is the consultation or treatment from ones who has professional health knowledge, who works for district hospital, provincial hospital, central hospital or other state facilities, private practitioners, private clinics and private hospitals including both western and traditional medicine.

Types of illnesses: The types of illness in this study are illnesses should have doctor's consultant before using medicine for treatment such as angina, tonsillitis, gastritis, etc. These diseases requires the relative special treatment, the dosage and time of taking medicine in treatment as well as the combination in using medicines, such as antibiotics or steroids.

Unit of analysis: This study observes the behaviour of those who had at least one times of using health care providers in the last three months, visiting doctor or visiting pharmacy, when being illness. In a period of sickness, a patient might have one or several times of using medical services. Therefore, unit of analysis in this study is not the individuals but their number of visits to medical services when being illness.

\section{LITERATURE REVIEW}

\subsection{Theory of consumer behaviour} and the demand for health care services

According to Jack (1993), the demand for health care services was described in the orthodox static utility-maximizing framework. To examine the effect of health status, income and price on the demand for medical care, the author supposed that individuals have preferences for health and they choose health care providers as the only input into the production of health. In the other hand, individuals use their limited available budget to seek a bundle of goods and medical services which maximize the satisfaction they can reach. Health is treated as one of several commodities in the bundle of goods that individuals have preferences.

The utility function is $U(c, h)$, where $c$ is denoted for all of alternative goods 
that individuals consume, and $h$ is the level of health that the individual want to gain. Assumed that medical care is the only input into production of health, individuals require $\theta$ (index of health status of individual) units of medical care to produce an additional unit of health. Given income $m$ and health status $\theta$, one faces a budget constraint $c+\theta h \leq m$, with assumption that the prices of consumption and medical care are both unity.

Figure 1: : Available Health consumption bundles for individuals with different health status

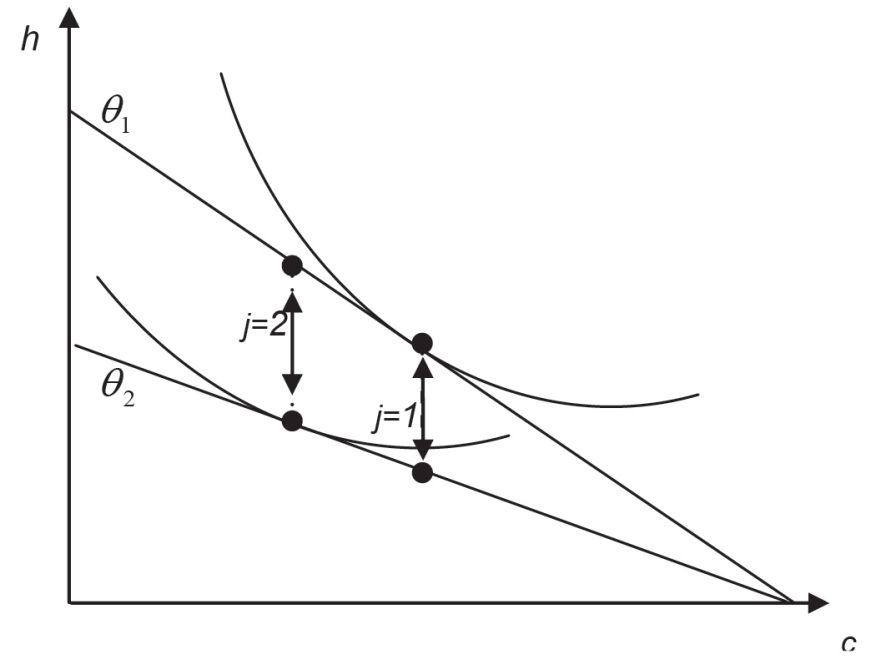

Source: William Jack, 1993

If an individual face a fixed number $n$ given provider in the two different states of of health care providers, and the assumption health are aligned vertically: the individual that cost of each provider is independent of chooses provider $j=1$ in situation health her health status, the points on the budget status $\theta_{1}$; when being sicker, $\theta_{2}$, she prefer lines of figure 1 corresponding the healthconsumption bundles combined with a provider $j=2$.

Figure 2 Effects of Income on Provider choices
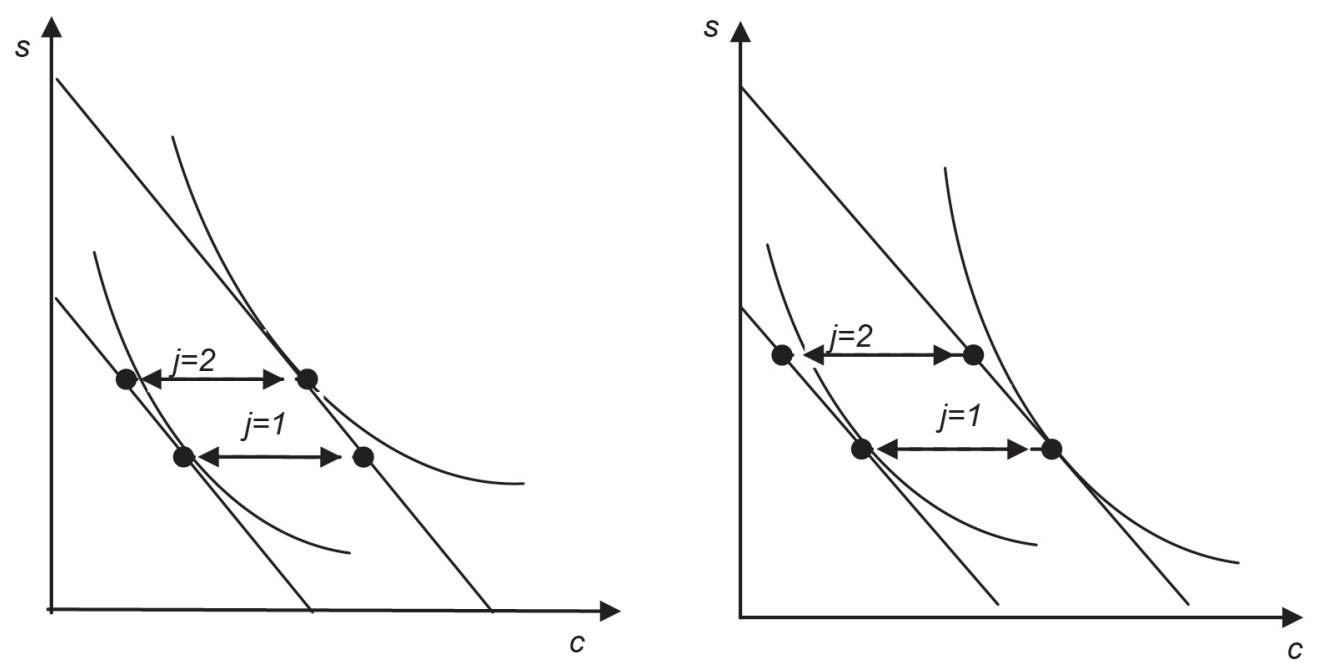

(Source: William Jack, 1997) 
The effect of income on provider choice: It's supposed that health and health care are normal goods. Given health status, an increase in income of an individual, budget constraints curve shifts to the right in figure 2a, lead to a change in demand for medical provider, other things being equal. If preferences are quasilinear with respect to the consumption good, income does not have effect on provider choices of individual, as shown in figure $2 \mathrm{~b}$. In that situation, health is not a normal good.

The effects of price on discrete demand: Have assumed that providers has produced the same improvement in health when price change. The only distinction is that the decrease in consumption of high-price provider is greater. The budget line for purchased services swings inward when the price of care goes up. The points indicate health-consumption bundles combine with given provider are horizontally displaced, given health state and income (figure 3). Other things be equal, an individual consumes at a lower level of services when providers offer higher prices.

\section{Figure 3: Effect of Price on Provider choice}

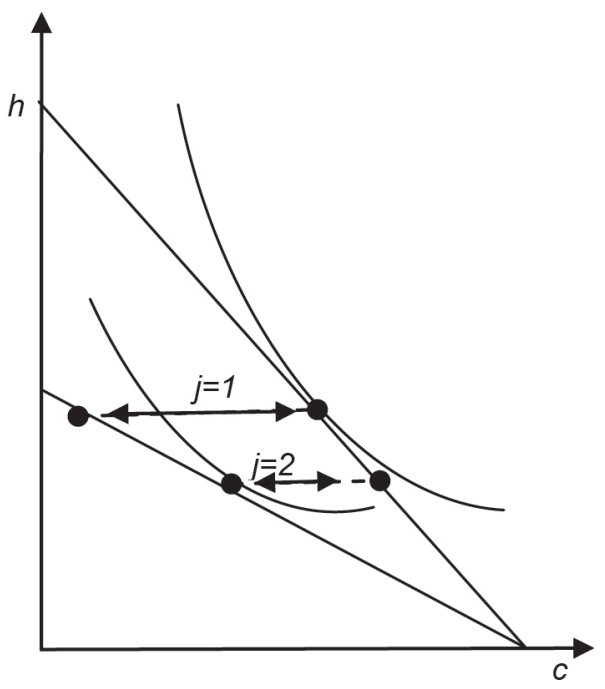

Source: William Jack, 1997

\subsection{Grossman's theory of human capital and the demand for health care}

The Grossman model explained how individuals allocate their resources to produce health. It utilises the idea of the individuals as a producer of health (not simply the consumer) and the idea of investing in human capital (health and education) to improve outcomes in both market sector of economy, where he works and earns money, and non-market sector of household, where he produces commodities that enter his utility function.

The utility function of a typical consumer is

$$
U=U\left(\phi_{i} H_{i}, Z_{i}\right)
$$

where $H i$ is the stock of health in the $i^{\text {th }}$ time period, $\phi_{i}$ is the service flow per unit stock. Hence, total consumption of health services is $h_{i}=\phi_{i} H_{i} . Z_{i}$ is total consumption of another commodity in the $i^{\text {th }}$ period. The key assumption of the model is that individual is born with an initial stock of health that depreciates with age and that can be added by investment. Therefore, the net stock of health in the $i^{\text {th }}$ time period is the gross investment deducts depreciation:

$$
H_{i+1}-H_{i}=I_{i}-\delta_{i} H_{i}
$$


where $I_{i}$ is gross investment and $\delta_{i}$ is the rate of depreciation during the $i^{t h}$ period. The demand of health care is derived from a demand for health and consists of two elements. First, as a consumption commodity, health yields direct utility and second, as an investment commodity, health increases the number of days available to participate in market and non-market activities. The investment decision of individuals in health is drawn from health production function:

$$
I_{i}=I_{i}\left(M_{i}, T_{H_{i}}, E_{i}\right)
$$

and consumption goods function:

$$
Z_{i}=Z_{i}\left(X_{i}, T_{C_{i}}, E_{i}\right)
$$

In these equations, $M_{i}$ is medical care, $X_{i}$ is goods input in the production of the commodity $Z_{i}, T_{H i}$ and $T_{C i}$ are the time spent on improving health and composite consumption good, and $E$ is the stock of human capital or education.

In this model, education plays a crucial role in determining the efficiency of health capital and also in other production functions. It means that the more educated would demand more health but less medical care because educated people are more efficient producers of health.

The model showed that the shadow price rises with age if the rate of depreciation on the stock of health rises over the life cycle. In other words, an increase in the shadow price, under certain conditions, may simultaneously reduce the quantity of health demanded and increase the quantity of medical care demanded.

Andersen's behavioural model and access to medical care

The social behavioural or Andersen's behavioural model defines three categories of determinants of demand for medical services: predisposing factors, enabling factors, and the need for care. This model was specifically developed to investigate the use of medical health services.

The demographic factors such as age, gender, religion, marital status, etc. Social structure is measured by a number of factors that determine the position of a person in the community, the physical environment is healthy or unhealthy, his or her ability to deal with presenting problems and commanding resources to deal with these problems,. The traditional measures used to assess social structure include education, occupation, and ethnicity.

Health beliefs are used to access how social structure impact on enabling resources, perceived need, and use of health services. Attitudes, values, and knowledge about health and health services of people are health beliefs that might affect their demand of health care.

There are some of important measures to evaluate enabling factors: health insurance, income, travel and waiting time, social network support, quality of medical services, costs of care, etc.

Predisposing characteristics and enabling factors influence perceived need which converts individual's subjective perception of his or her health status and the need for care into demand for medical care and taking steps to get treatment. This leads to specific health seeking behaviour.

Chang and Trivedi (2003):

This model investigates the choice of an individual between self-medication and other professional health care providers using the data from Vietnam (VLSS 1997 - 1998). They assumed that an individual with a given income $y$ will choose the combination of the health status $h$ and the consumption $c$ to gain the highest utility, the utility function form is $U(c, h)$. To improve one's health status, an individual has two providers of health care: professional care $V$ or self-medication, $Q$. The model 
focus on the problem of choosing health care providers, so the price of professional care $V$ is set as unity. By doing that, the parameter $p$ in the budget constraint equation (1)

$$
y=c+V+p Q
$$

is also the relative price of selfmedication $\mathrm{Q}$ to professional care $\mathrm{V}$.

The consumption function can be derived from (1):

$$
c=y-V-p Q
$$

Suppose that $h_{0}$ is initial health status of an individual, the function of health level of one is:

$$
h=h_{0}+R V+(R-\varepsilon) Q
$$

The function shows that one gains the return to professional care $R>0$, suppose that professional care is risk-free, and the return to self-medication is $R-\varepsilon$, where $\varepsilon$, such as medication errors because of wrong diagnosed, is a random variable with $E(\varepsilon)>0$. It implies that patient who use self-medication may be less efficient than professional care.

Substituting (1) and (2) into the utility function $U=U(c, h)$, we yields the general indirect utility function:

$$
U=U\left(y-V-p Q, h_{0}+R V+(R-\varepsilon) Q\right)
$$

The equation (4) shows that an individual's welfare depends on the consumption level of other goods except health care, and the one's expected health status by spending money to receive treatment from professional health care provider and self-treatment.

\section{Arjun S.Bedi et al (2003):}

The model used data from Kenya to explain the behaviour of individual facing illness in choosing among alternative health care providers, such as government provider, private provider, other health facility and self-care. This model suggests the utility function of individuals, conditioning to be illness is:

$$
U_{i j}=U\left(H_{j}, C_{j}\right)
$$

Where $H_{i j}$ is health status of one who chooses health care providers $j$ for treatment when being illness, $C_{i j}$ is the consumption of all other goods. And the health production function is

$$
H_{i j}=H\left(X_{i}, Z_{j}\right)
$$

This equation shows that the expected improvement of health status depends on attributes of an individual $X_{i}$ and $Z_{j}$, the quality of health care provider $\mathrm{j}$ received by the individual.

With $Y_{i}$ is the income of an individual and $P_{j}$ is the cost associated with buying treatment from the health care provider $j$, the consumption function shows the consumption level of individuals subject to their income and the expense of medication care received from one health care provider $j$ should be:

$$
C_{i j}=Y_{i}-P_{j}
$$

By substituting the health status equation (6) and the consumption function (7) into the utility conditional function (2.9), it gains a general utility function

$$
U_{j i}=U\left(X_{i}, Z_{j}, Y_{i}, P_{i}\right)
$$

The equation (2.12) describes an individual can gains the benefits from choosing a typical health care provider under conditions of characteristics of an individual $X$, the attributes of the provider $Z$, the individual's income $Y$, user fees $P$ paid for visiting provider $j$.

To determine the probability of choosing a typical health care provide, the authors adopted a linear utility specification, then the general utility function may be rewritten as follow: 


$$
U_{i j}=V_{j}+\varepsilon_{j}
$$

Where $V_{i j}$ is the systematic part of the utility function and depends on attributes of individual and quality of health care provider, $\varepsilon_{i j}$ is residual. Thus, the utility function should be:

$$
\begin{array}{r}
U_{i j}=\alpha_{j} W_{j}+\beta_{j} K_{j}+\varepsilon_{j}, \quad \text { where } \\
W_{i j}=\left[X_{i}, Y_{i}\right] \text { and } K_{i j}=\left\lfloor Z_{j}, P_{j}\right\rfloor
\end{array}
$$

Let $\mathrm{HCP}_{\mathrm{i}}$ is health care provider indicator, the health care provider choice of an individual may be presented as

$$
H C P_{i}=j \text { if } U_{i j}>\max \left\{U_{i k}\right\}
$$

The individual $i$ will choose the health care provider $j$ if the expected utility received from it is higher than the other ones.

\section{MODEL SPECIFICATION}

Whereas the consumer theory treats health as one of the several commodities over which individuals have well-defined individual preferences, the Grossman's model treats health as a stock variable within human capital framework. It's suggested that in human capital theory, the measures used to capture the consumption value of improved health status are lower bounds while demand for health services is more easily observed and quantified in the consumer theory (Jack, 1993). The Andersen's model provides the way to integrate a number of ideas about the "how's" and "why's" of health services' use.

The first empirical study presented in section 2.4, Chang and Trivedi's model, suggests an explanation of how individual allocation theirgiven income in two ways of treatment: self-mediation and professional health care providers. However, it does not show the one's health care choice if they are illness. The second one gives a way to explain the choices of those who "pertain only to public facilities", in case of multiple health care providers.

Thus, constructing an appropriate empirical model to answer the research question needs some justifications based on the above analyses about theoretical framework and empirical studies.

\section{Empirical model}

It's assumed that an individual when being illness will have to choose between self-medication and professional health care provider, the utility from the two alternatives providers:

$$
U_{i j}=U\left(Y_{i}-P_{j}, X_{i}, Z_{j}, \varepsilon_{j}\right)
$$

Where $\left(Y_{i}-P_{j}\right)$ has the same meaning with the equation (7), $X_{i}$ is the consumer preferences, $Z_{j}$ is the quality of the provider $j$, and $\varepsilon_{i j}$ is the unobserved components. Supposed that the consumer will choose self-medication if expected utility is higher than that from professional health:

$$
U_{1 i}=U\left(Y_{i}-P_{1}, X_{i}, Z_{1}, \varepsilon_{1 i}\right)>U\left(Y_{i}-P_{0}, X_{i}, Z_{0}, \varepsilon_{0 i}\right)
$$

Where $j=1$ if individual choose self- of choosing self-medication, the equation medication and $j=0$ for professional should be:

health care. To estimate the probability

$$
\operatorname{Pr}(j=1)=\mathrm{P}\left(U\left(Y_{i}-P_{1}, X_{i}, Z_{1}, \varepsilon_{1 i}\right)>U\left(Y_{i}-P_{0}, X_{i}, Z_{0}, \varepsilon_{0 i}\right)\right)
$$


It's assumed that the utility function is linear; the equation (14) is separable in deterministic and stochastic preference:

$$
U_{i j}=V\left(Y_{i}-P_{j}, X_{i}, Z_{j}\right)+\varepsilon_{j}
$$

The deterministic part of utility can be presented as follow:

$$
V_{i j}=\alpha_{j}\left(Y_{i}-P_{j}\right)+\sum_{e=1}^{t} \beta_{\dot{e}} X_{\dot{e}}+\sum_{k=1}^{m} \lambda_{k} Z_{k}
$$

From the equation (16), the deterministic part of utility from selfmedication is:

$$
V_{1 i}=\alpha_{1}\left(Y_{i}-P_{1}\right)+\sum_{e=1}^{t} \beta_{1 e} X_{\dot{e}}+\sum_{k=1}^{m} \lambda_{1 k} Z_{1 k}
$$

And the utility from professional health care provider is:

$$
V_{0 i}=\alpha_{0}\left(Y_{i}-P_{0}\right)+\sum_{e=1}^{t} \beta_{0 e} X_{\dot{e}}+\sum_{k=1}^{m} \lambda_{0 k} Z_{0 k}
$$

As mentioned before, the utility function is linear, thus the marginal utility of income of an individual in the two situations should be identical:

$$
\begin{aligned}
& V_{1 i}-V_{0 i}=\alpha_{1}\left(Y_{i}-P_{1}\right)+\sum_{e=1}^{t} \beta_{1 e} X_{\dot{e}}+\sum_{k=1}^{m} \lambda_{1 k} Z_{1 k}-\alpha_{0}\left(Y_{i}-P_{0}\right)+\sum_{e=1}^{t} \beta_{0 e} X_{0 e}+\sum_{k=1}^{m} \lambda_{0 k} Z_{0 k} \\
& V_{1 i}-V_{0 i}=\alpha p+\sum_{e=1}^{t} \beta_{e} X_{\dot{e}}+\sum_{k=1}^{m} \lambda_{k} Z_{1 k}
\end{aligned}
$$

The probability statement (20) could be rewritten as follow:

$\operatorname{Pr}(j=1)=\mathbf{P}\left(\alpha p+\sum_{e=1}^{t} \beta_{e} X_{\dot{e}}+\sum_{k=1}^{m} \lambda_{k} Z_{1 k}>0\right)$

The probability function (21) expresses the choice between selfmedication and professional care of an individual facing illness will depend on difference in prices of the two, individual preferences, and attributes of health care providers. As a result, the regression function could be:

$$
S_{i}=\alpha_{0}+\alpha_{1} X_{1}+\alpha_{2} X_{2}+\beta_{3} Z_{3}+\varepsilon
$$

The dependent variable in our regression function takes on two different values, one for self-medication and zero for professional health care providers. The econometric estimation methods used in the study involves limited dependent variables. Thus, the binomial logit model is used to analyse such discrete variable in this study.

$$
\boldsymbol{h}\left(\frac{P_{r}}{1-P_{r}}\right)=\alpha_{0}+\alpha_{1} X_{1}+\alpha_{2} X_{2}+\alpha_{3} Z_{3}+\varepsilon
$$

Where $r=0,1$ representing the two possible alternatives of patients, selfmedication and professional care. $P_{r}$ is the probability of choosing the two options of individuals facing illness. The regression function shows the choice of patients will depend on difference in prices $\left(X_{1}\right)$, characteristics of individual $\left(X_{2}\right)$ and attributes of the two health care providers $\left(Z_{3}\right)$. 
Transforming theoretical framework into variables

Table 1. List of variables and Expected Signs

\begin{tabular}{|c|c|c|}
\hline Variables & Description & Expected signs \\
\hline \multicolumn{3}{|c|}{ Dependent Variable: Choice of provider conditional on being sick } \\
\hline choice & $=1$ Self-medication, professional health care $=0$ & \\
\hline \multicolumn{3}{|c|}{ Independent Variables: } \\
\hline \multicolumn{3}{|c|}{ Difference in price $\left(X_{1}\right)$} \\
\hline difpri & Difference in cost for getting medical services & + \\
\hline \multicolumn{3}{|c|}{ Characteristics of individual $\left(\mathrm{X}_{2}\right)$} \\
\hline edu & Completed years of education & + \\
\hline age & Age in years & - \\
\hline gender & $=1$ Male $;=0$ Female & - \\
\hline married & $=1$ if married $;=0$ otherwise & + \\
\hline dayill & Number of days of illness & + \\
\hline ins & $0=$ Uninsured $; 1=$ Insurance & - \\
\hline \multicolumn{3}{|c|}{ Attributes of health care providers $\left(\mathrm{Z}_{3}\right)$} \\
\hline diftime & Difference in time for getting medical services & + \\
\hline quality & $\begin{array}{l}\text { Quality of professional health care provider: }=1 \text { if patient } \\
\text { agree that he would be sooner recover from illness if they had } \\
\text { received consultations form professional health care provider; }= \\
0 \text { otherwise }\end{array}$ & - \\
\hline
\end{tabular}

\section{Dependent variable:}

The left hand side of regression function (2.27) is a dummy variable referring to the choice of an individual $i$, 1 for self-medication, 0 for visiting doctor.

\section{Independent variables}

\section{Difference in price $\left(X_{\nu}\right)$ :}

About effect of price on health care seeking behaviour, the previous researches found quite mixed results. Litvack and Bodart (1993), Lavy and Germain (1994) proved that price has strong significant effects on health demand. Meanwhile, Lacroix and Alihonou (1982), Akin et al. (1998) and WB (1987) concluded that price has relatively little influence on health care demand.

Price includes not only direct monetary payments for goods and services but also additional costs in consuming medical care such as forgone income and travel costs. To consumers who are enrolees in health insurance, sometimes forgone consumption for medical services is relatively small or equal zero compare to those who work in informal labour markets and not enrol in health insurance programs. According to Jack (1997), travel costs enable researchers to investigate health care demand in case there is little variation in observed money prices. Travel costs even use as the only measurable costs for health care in study of Gertler and Van der Gaag (1990).

However, the focus of this study is the effects of educational level on choosing health care provides of individuals and because of the limitation of data collection, the travel costs are 
supposed equal zero. Therefore, the price self-medication in this study includes monetary payments for medicine and for those who visit professional health care providers, the price is consumption of prescribed medicine and consultant fee as an additional cost.

The difference in price is result of subtracting total cost of self-medication for total cost of visiting doctor. The difference in price is expected to have positive effects on probability of choosing self-medication over visiting doctor.

\section{Patient characteristics $\left(X_{2}\right)$}

This part will introduce variables of individual characteristics which affects his or her choices about what kind of medical services into econometric model:

Age is measured by the number of years in age.

\section{Gender}

\section{Marital status}

Education is measured by schooling years of respondents. Empirical studies have contrary conclusions about the effect of education level on probabilities that selfmedication will be chosen. In Vietnam, Chang and Trivedi (2003) concluded that the more educated individuals, the better aware of the risks of self-medication they have. A study of Bedi et al. (2003) in Kenya found that more educated individuals would rather consult a doctor instead of treating by themselves when they fall sick. Meanwhile, in study about self-medication in rural communities in Vietnam, Okumura (2002) found that people who are higher levels of education are more likely self-medication in event of illness. Another study in Sudan of Awad et al. (2005) showed that self-medication was highest behaviour among the individuals who are higher levels of education. Thus, it's expected that the effects of educational attainment on self-medication are similar to empirical of Okumura (2002) and Awad et al.

\section{Dayill}

This variable is measured by number of days of illness, as an additional proxy for health status. People who have more number of days of illness tend to visit professional health care providers. Hence, a negative sign is expected for the effect of this variable on self-medication behaviour.

\section{Attributes of health care providers $\left(Z_{3}\right)$ :}

Attributes of medical services have many ways to measure. Akin and Hutchinson (1999) used number of beds, number of doctors, hours open per week, drug availability and services provided to capture the quality of medical services. However, this study just focus on the types of illness which not last over thirty days and not need to be inpatient, and all of the health care providers in our data are in Ho Chi Minh city leading to there are little variances in these types of measure. Thus, the number of methods discussed above seems not appropriate to measure quality of health care provider for this study. The other studies suggested that post natal medical services, physical facilities, the level of cleanliness of the medical centre, provider's medical experiences, etc (Akin et al., 1995, Besley et al., 1999) are the measures of quality of medical services. However, the consuming time (Jack, 1993) appears to the best method to estimate attribute of health care providers because the respondents can easier report about such kind of information.

It's expected that when individuals decide to seek professional health care providers, besides travel time, they have to compare the time for self-medication with the significant extra forgone time for professional health care provider, such as 
the waiting time at clinics or hospitals, and the time seeing doctor. Thus, total consuming time of visiting doctor appears to be greater than of visiting pharmacy. It's reasonable when expect that the effect of difference in time, result of comparing total consuming time of visiting professional health care providers to that of visiting pharmacy, on the probabilities of selfmedication is positive.

Another variable, quality of description, is used as a proxy of quality of professional health care providers. The quality of prescription is captured by the agreement of respondents when answer questions "whether they would recover from illness sooner if they visit a doctor", in the case they chose self-medication only or just consult doctor after visiting pharmacies.

\section{EMPIRACAL RESULTS \\ DATA COLLECTING METHOD}

Cross sectional data for the analysis comes from household survey was conducted in Ho Chi Minh city by the author through structured interviews. Due to the time and budget constraints, three inner districts were selected randomly to do the survey: District 1, District 3, and Tan Binh District. The sample size was computed from the formula in Mason, $\mathrm{R}$. D (1999: 292):

$$
n=p(1-p)\left(\frac{Z}{E}\right)^{2}
$$

\section{Where:}

$n$ is the size of the sample;

$p$ is sample proportion;

$Z$ is the standard normal value corresponding to the desired level of confidence;

$E$ is the maximum allowable error.

Since the term $p(1-p)$ is maximized at $p=0.5$ and $p$ is not identified, the value of $\mathrm{p}$ is set at 0.5 . $\mathrm{Z}$ equals 1.96 at the level of confidence of $95 \%$ and $E$ is 0.1 .

Applying the Equation (4.1), the sample size needed is equivalent 97.

However, the sample size was set to 120 because the logit model will be used to answer the research question of this study. Following the suggestion of Long (1997:54) that at least 10 observation per parameter seem reasonable for maximum likelihood estimation.

The study primary data was collected through interview technique in HoChiMinh city. The pilot survey of 30 respondents for pre-testing the questionnaire carried out before the main survey. A face to face interview with structured questionnaires, each lasting about 25 minutes was conducted at the respondent's home. The main survey carried out within 4 weeks in May, 2009 interviewed 120 patients with the total of 227 contacts medical services.

The questionnaire has four parts to acquire necessary information. The first part includes questions to access respondents' knowledge about drug safety and attitude toward self-medication. These questions were designed by the recommendation of Dr. Nguyet and Dr. Quang from ShiHospital in Ho Chi Minh city. Before going to the next part, respondents will be asked whether they had been sick during the three months period prior the survey. The interview was not continued if the illnesses that respondent had been were not in the list and not use of any medical services.

The respondents were asked about number of days of illness, types of health care providers they sought, number of contacts and their appraisement about quality of prescription in the second part.

The third part asked patients' information about the attributes of health 
care provider they chose and amounts paid for medicine and consultation. Depending on the types of medical services they had chosen in the former part, respondents were divided into three groups: (1) choosing self-medication only; (2) visiting doctor only; (3) both types of medical services. Firstly, group (1) and (2) were given questions about actual medical service they chose. Then, they was asked similar question with the assumption that they had chosen the alternative providers. The purpose of asking these questions is to avoid missing values when patients chose only one type of medical service.

The last part consists of questions to observe individual's characteristics such as education, age, gender, marital status, ethnic, occupation, etc.

\section{DATA DESCRIPTION}

As mentioned, this study is interesting in the choice of an individual between pharmacy and clinic/hospital facing illness, and the factors associating with these two outcomes. Therefore, unit of analysis in this study is the number of visits to medical services such as pharmacy or clinic/hospital. The household survey data conducted by author has 120 participants with 227 contacts with health care provider. Therefore, we have 227 observations to regress empirical model. This section will report regression result and interpretations.

The average schooling year is 9.45 . The schooling years of education level varies from 2 to 16 . The ages of respondents varies from 18 to 68 with their mean age in years is 33.22. The numbers of female and male respondents are equal, and $38 \%$ of them are single. The average day of illness is 7.45 varying from 1 to 30 days. There are $47(39 \%)$ respondents reported that they enrol in the health insurance program.

To describe behaviour of individuals facing illness in more detail, the survey data was divided into 3 groups of behaviour: group 1 for those who only chose selfmedication, group 2 for those who only chose to visit doctor, and group 3 for those who have both behaviours ${ }^{1}$. There are 60 respondents in Group 1, 24 respondents in group 2 and 36 respondents in group3.

According to the data survey, the proportion of respondents in secondary educational level is highest among 3 groups. The individuals with college/university level seems more likely self-medication only, take $28.3 \%$ of group 1 and just $4 \%$ of group 2. It implies that the individuals in higher educational level prefer visiting pharmacy to consulting doctor.

For group 3, describing how individuals changed their choice of health care providers through their treatment times helps us have a more clearly view about consumer behaviour facing illness. The information from data shows that people in group 3 firstly tend to visit pharmacies, and then they consider consulting doctor. However, if they have to continue their cure, they prefer self-medication to taking medical advice. This can be explained because patients did not re-examination but used previous prescription to buy medicine for themselves.

The questionnaire also has ten questions to access respondents' knowledge level of drug safety. The result of this test implies that those who visited a doctor are probably better informed about the information of the appropriate medicine using. However, even though the mean scores of knowledge increase with educational level, these figures strongly indicate that respondent's knowledge level was less than satisfactory.

${ }^{1}$ For the rest of this paper, Group 1, Group 2, and Group 3 are used instead self-medication only, visiting doctor only and both behaviours respectively. 


\section{ECONOMETRIC ANALYSES}

Education level has positive effect on the self-medication choice as expected. In detail, for each additional year of education level, the odds of choosing self-medication are increased 11 per cent, holding all other variables constant. We can conclude that the prevalence of self-medication in Ho Chi Minh city trend to be higher among people with a higher education.

Age has a negative effect on selfmedication behaviour or the older prefer consulting from doctor to visiting pharmacy. This suggests that for a year increase in age the log of the odds in favour of self-medication decreases about 0.03 , holding all other variables unchanged.

Women are more likely selfmedication than men, the predicted probability of a male patient who visit pharmacy is $55 \%$, of a female patient is $81 \%$, holding all other variables at their means. It means that the probability of choosing self-medication for a woman is 0.26 greater than a male, holding all other variables at their means.

\section{Table 2 : Logit Regression Results}

Logit estimates

Log likelihood $=$ $-99.34$

Number of obs $=227$

$\mathrm{LR}$ chi2(9) $=98.30$

Prob $>$ chi $2=0.0000$

\begin{tabular}{|l|l|l|l|l|}
\hline \multicolumn{5}{|l}{ Dependent variable: CHOICE $(0$ for visiting doctor; 1 for self-medication $)$} \\
\hline Independent variables & Coef. & Odds Ratio & $\mathrm{z}$ & $\mathrm{P}>\mathrm{z}$ \\
\hline edu & 0.107 & 1.112 & 2.09 & 0.037 \\
\hline age & -0.029 & 0.972 & -1.71 & 0.088 \\
\hline gender & -1.211 & 0.298 & -3.08 & 0.002 \\
\hline married & -1.106 & 0.331 & -2.53 & 0.011 \\
\hline dayill & -0.055 & 0.947 & -1.26 & 0.207 \\
\hline difpri & 0.005 & 1.005 & 2.29 & 0.022 \\
\hline diftime & 0.020 & 1.020 & 1.73 & 0.084 \\
\hline quality & -1.435 & 0.238 & -2.45 & 0.014 \\
\hline ins & -0.951 & 0.386 & -2.39 & 0.017 \\
\hline
\end{tabular}

Source: Data regression from author's survey 2009

Marital status is significant negative effects but get an opposite expected sign. The discrete change in probability of visiting pharmacy from a married individual to a single one is 0.22 . This implies that the married respondent who prefer consulting doctor to visiting pharmacy, with 0.22 greater probability than single one.

The number days of illness get the expected sign but insignificant effects on choosing health care provider. This implies that the length of illness day does not explain for the behaviour of individual when being illness.

Difference in cost appeared to be positively related to self-medication as expected. As regression result shows, the estimated slope coefficient suggest that for a unit $(1,000 \mathrm{VND})$ increase in different in price the log of the odds in favour of choosing self-medication goes up by about 
0.005 . This small change in factor change implies that facing two choices of health care providers, prices of those are not a strong indicator which affects decision of individual.

Meanwhile, the effect of different in time on the probability that respondents chose pharmacy visit over doctor consultation is relatively stronger. For one minute increase in consuming time of consultant doctor compared to selfmedication, the odds of choosing visiting pharmacy increased $2 \%$, hold all other variables constant.

As expected, two dummy variables about the quality of prescription and health insurance status decrease the probability of choosing self-medication. This former dummy variable shows that if respondents who agree that visit doctor make sign of illnesses relieve sooner, their probability visiting pharmacy is 0.24 smaller than those disagree. And probability of health insured patients who chose selfmedication is 0.20 smaller than those who are uninsured health.

\section{CONCULSION SUGGESTION}

\section{CONCLUSIONS}

In this study we model health care provider choice in Ho Chi Minh city with a binary logit model using household survey data conducted by the author. The regression results agreed with the hypothesis that education level plays an important role in individual's decision of choosing self-medication facing illness. The more educated they are, the more selfconfidence they have in treating minor illness by self-medication. However, the descriptive statistics showed that the level knowledge of safe medicine use is relatively low among patients. The lack of knowledge about safe medicine use accompanied with the prevalence of self-medication among respondents has contributed the emergence of drug resistance, resulting in wastage of resources; unsuccessful in treatment of relatively cheap drugs that claim for new drugs development. The cost of newer, broad-spectrum antibiotics is a financial burden against in developing country like Vietnam (WHO, 2001a).

Beside education level, the others demographic variables have significant effects on individual behaviour of choosing health care providers. The older has negative relation to a person visit drug store. The possible explanation for this is those papers analysed the data included chronic diseases which make the older tend to self-medicate because no remedy or they purchased drugs using an old prescription.

The gender gap between male and female is positive. The fact that woman prefer choosing self-medication to visiting doctor is an evidence proves that woman faces a higher time constraint than man when self-medication has been considered as a more convenient choice in terms of time.

The marital status has positive effect on self-medication. In other word, the married people are less likely to visit pharmacy. A single person faces a higher probability of self-medication than married one.

This study found that the different in time and different in price have positive effect on choosing pharmacy visit of individuals. The different in time, however, has a higher effect. In other word, facing between longer consuming time and higher monetary payments, patients appear to be more interested in the former.

The enrolment of health insurance programme plays a significant role in 
choosing health care providers of patients. The enrolee have positive attitude toward visiting doctor.

\section{SUGGESTIONS}

According to the results of this study, we suggest a number of recommendations in order to improve the benefits and diminish the risks of self-medication.

First, government should give more interventions by public medical education programs to improve knowledge about drug and safe medication practices for the public in order to help them to be able to make appropriate decisions about their own health. The low level of medical knowledge among high educational people suggests that more medical educational efforts are needed to correct misunderstanding for people from being in school. The means of communication such as television, radio, newspaper should be encouraged to provide more information about safe using of drugs, the risks of increasing antibiotics resistance, ect. According to the results of this study, public medical education should focus on people with a higher education, those are young (below the age of 45), single and female.
Second, partnership between doctors, pharmacy staff and patients should be enhanced according to the purpose of minimising risk and maximising benefit of self-medication.

The convenient in accessing professional health care providers is also an important factor to encourage people have more demand on medical examination when being illness. Reducing the waiting time in clinics and hospital appears a rational solution when people attach important to consuming time more than price.

The negative effect of health insurance status on self-medication supports the expanding population coverage of health insurance programmes. According to VNHS 2001, the insured use less private facility services as a result of the fact that the insurance only covers public facility services. However, the study of World Bank (2001) also shows that the private sector plays an important role in providing outpatient services. Giving to private sector a greater official role in health insurance programs would increase the overall efficiency of health professional in Viet Nam. 


\section{REFERENCES}

Andersen, R.M. 1968 "A behavioural Model of Families's Use of Health Services". Research series No.25. Chicago: University of Chicago, Centre for Health Administration

Andersen, R.M. 1995 "Revisiting the Behavioural Model and access to medical care: does it matter?" Journal of Health and Social Behaviour,36:1-10

Bedi, A., Kimalu, P., Kimenyi M. W., Manda D. K., Mwabu, G. and N. Nafula (2003) "User Charges and utilisation of Health Services in Kenya" Working paper No. 381, Institute of Social Studies, the Hague, The Netherlands

Chang F, Trivedi PK (2003) "Economics of self-medication: theory and evidence", Health Economics, John Wiley \& Sons, Ltd., vol. 12(9), pages 721-739

Chuc, N.T. and Tomson, G. (1999). "Doi Moi" and private pharmacies: a case study on dispensing and finacial issues in Hhanoi, Vietnam. European journal of clinical pharmacology, 55: $325-332$

Grossman, M. (1972) “On the Concept of Health Capital and the Demand for Health", Journal of Political Economy, Vol 80:223-255

GSO (1999). Vietnam Living Standards Survey 1997-1998. General Statistical office, Hanoi

Gujarati D.N. (2003) Basic Econometrics, McGraw-Hill, 2003

Ha, N. (1991), "Resistance to antibiotics in enteric bacteria from patients with diarrhoea and healthy persons in Vietnam and characterization of beta lactamases in eschericha coli", (Thesis) Academic Department, Karolinska Institutet, Stockholm

Ho Chi Minh GSO (2005), Statistical Yearbook Ho Chi Minh city, Statistical office of Ho Chi Minh city (Vietnamese version)

Jack, W. (1993) "The Demand for health Care Services", Principles of Health Economics for Developing countries, WB I Development Studies, Washington, DC, 55-79.

James H, Handu SS, Al Khaja KAJ, Otoom S, and Sequeira RP (2006),

"Evaluation of the Knowledge, Attitude and Practice of Self-Medication among FirstYear Medical Students", Medical Principles and Practice, 15:270-275

Long,J.S(1997), Regression Models for Catergorical and Limited Dependent Variables, London \& New Delhi:Sage Publications

UN (2003) “ Vietnam: Economic Development Indicators, 1995-2000” http://www. un.org/esa/population/publications/countryprofile/vietnam.pdf, accessed on 20 February, 2007

Van Duong, D.V., Binns, C.W., \& Le, T.V. (1997) "Availability of antibiotics as overthe counter drugs in pharmacies: A threat to public health in Vienam". Tropical Medicine \& International Health, 2(12), 1133 - 1139

VNHS (2001-2002), http:/www.moh.gov.vn/solieu/defaultE.htm, accessed on 20 August, 2006

World Bank (1993). World Development report. Investing in health. World Band Publications, Washington.

World Bank (2001). "Vietnam: Growing Healthy - A Review of Vietnam's Health 
Sector". World Bank Publications, 2001

WHO (2001a) "Global Strategy for Containment of Antimicrobial Resistance", World Health Organization, Geneva

WHO (2001b) "Guidelines for the regulatory assessment of Medicinal Products for use in self-medication". WHO Drug Inform 2001, World Health Organization, Geneva 